\title{
Simulation of the soil water balance of wheat using daily weather forecast messages to estimate the reference evapotranspiration
}

\author{
J. B. Cai ${ }^{1}$, Y. Liu ${ }^{1}$, D. Xu ${ }^{1}$, P. Paredes ${ }^{2}$, and L. S. Pereira ${ }^{2}$ \\ ${ }^{1}$ Department of Irrigation and Drainage, China Inst. of Water Resources and Hydropower Research, Beijing 100044, China \\ ${ }^{2}$ Agricultural Engineering Research Center, Inst. of Agronomy, Technical University of Lisbon, Tapada da Ajuda, \\ 1349-017 Lisbon, Portugal
}

Received: 16 December 2008 - Published in Hydrol. Earth Syst. Sci. Discuss.: 5 February 2009

Revised: 11 May 2009 - Accepted: 25 June 2009 - Published: 9 July 2009

\begin{abstract}
Aiming at developing real time water balance modelling for irrigation scheduling, this study assesses the accuracy of using the reference evapotranspiration $\left(\mathrm{ET}_{o}\right)$ estimated from daily weather forecast messages $\left(\mathrm{ET}_{o, \mathrm{WF}}\right)$ as model input. A previous study applied to eight locations in China (Cai et al., 2007) has shown the feasibility for estimating $\mathrm{ET}_{o}$, wF with the FAO Penman-Monteith equation using daily forecasts of maximum and minimum temperature, cloudiness and wind speed. In this study, the global radiation is estimated from the difference between the forecasted maximum and minimum temperatures, the actual vapour pressure is estimated from the forecasted minimum temperature and the wind speed is obtained from converting the common wind scales into wind speed. The present application refers to a location in the North China Plain, Daxing, for the wheat crop seasons of 2005-2006 and 2006-2007. Results comparing $\mathrm{ET}_{o}, \mathrm{WF}$ with $\mathrm{ET}_{o}$ computed with observed data $\left(\mathrm{ET}_{o, \text { obs }}\right)$ have shown favourable goodness of fitting indicators and a RMSE of $0.77 \mathrm{~mm} \mathrm{~d}^{-1}$. $\mathrm{ET}_{o}$ was underestimated in the first year and overestimated in the second. The water balance model ISAREG was calibrated with data from four treatments for the first season and validated with data of five treatments in the second season using observed weather data. The calibrated crop parameters were used in the simulations of the same treatments using $\mathrm{ET}_{o, \mathrm{WF}}$ as model input. Errors in predicting the soil water content are small, 0.010 and $0.012 \mathrm{~m}^{3} \mathrm{~m}^{-3}$, respectively for the first and second year. Other indicators also confirm the goodness of model predictions. It could be concluded that using $\mathrm{ET}_{o}$ computed from daily weather forecast messages provides for accurate model predictions and to use an irrigation scheduling model in real time.
\end{abstract}

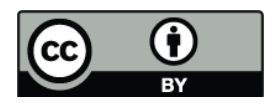

Correspondence to: L. S. Pereira (lspereira@isa.utl.pt)

\section{Introduction}

Recent developments in irrigation management consist in tools to support real-time irrigation decision-making. Their adoption requires that appropriate weather data are available to perform soil water balance computations for accurately determine the timing and volumes of irrigation. Realtime irrigation scheduling has proved appropriate when using weather data forecasts provided by commercial services to estimate the reference evapotranspiration $\left(\mathrm{ET}_{o}\right)$. Applications are reported for several crops such as potato (Gowing and Ejieji, 2001), lettuce (Wilks and Wolfe, 1998) and maize (Cabelguenne et al., 1997). In alternative to weather data forecasts, generated weather data produced by a climatic data generator may also be used (Donatelli et al., 2003; Stöckle et al., 2003, 2004).

Another approach to real-time irrigation scheduling consists of deriving actual crop coefficients $\left(K_{c}\right)$ from remote sensing and using ground and satellite weather data to estimate the actual crop evapotranspiration $\left(\mathrm{ET}_{c}\right)$ for determining irrigation requirements. Various applications and modelling approaches are reported with applications for estimation of actual $\mathrm{ET}_{c}$ at regional or irrigation system scales (Ray and Dadhwal, 2001; Consoli et al., 2006; Tasumi and Allen, 2007). At the field scale, Hunsaker et al. (2005) developed a model for determining wheat basal crop coefficients from observations of the normalized difference vegetation index (NDVI) and to estimate wheat evapotranspiration using the FAO-56 procedures. Chavez et al. (2008) computed daily $\mathrm{ET}_{c}$ from instantaneous latent heat flux estimates derived from digital airborne multispectral remote sensing imagery. Reviews are presented by Courault et al. (2005) and Gowda et al. (2008). Applications aiming at using crop coefficients estimated from remote sensing for supporting irrigation scheduling have been reported recently (Calera Belmonte et al., 2005; Garatuza-Payan and Watts, 2005; Santos

Published by Copernicus Publications on behalf of the European Geosciences Union. 
et al., 2008). The mentioned applications refer to large fields; when small fields (0.1-0.5 ha) are considered, as it is the case in China, the use of remote sensing data is not appropriate due to pixel size limitations.

To develop real-time irrigation management for North China, a different approach was developed by combining weather data forecast messages produced by the China Meteorological Administration with an irrigation scheduling simulation model. This approach allows to determine in realtime both the crop evapotranspiration $\left(\mathrm{ET}_{c}\right)$ and the available soil water, thus to determine when and how much to irrigate.

The FAO Penman-Monteith reference evapotranspiration (PM-ETo) equation (Allen et al., 1998) is worldwide adopted as the standard method to compute $\mathrm{ET}_{o}$ from meteorological data. Its computation requires weather data on maximum and minimum temperature $\left(T_{\max }\right.$ and $T_{\min }$ ), solar radiation $\left(R_{S}\right)$, relative humidity $(\mathrm{RH})$ and wind speed at $2 \mathrm{~m}$ height $\left(u_{2}\right)$. Alternative calculation procedures proposed by Allen et al. (1998) to be adopted when not all these data are available were tested and validated in China (Liu and Pereira, 2001; Pereira et al., 2003a) and elsewhere (Popova et al., 2006b; Jabloun and Sahli, 2008).

Considering that good results were obtained for North China using those alternative procedures, a new analytic methodology for computing the PM-ETo equation using weather forecast messages (WF) has been developed (Cai et al., 2007). It was tested for several locations in China at different latitudes and longitudes representing various climates. $\mathrm{ET}_{o}$ estimated with WF data can thus be used as input to a simulation model for real-time irrigation scheduling. Testing this approach using the model ISAREG, which has been previously calibrated and validated in North China (Liu et al., 1998, 2006), constitutes the main objective of this research. This research shall be further continued to spatialize both the WF data and model outputs to be used at project, basin or region level with several of crops.

The purpose of this paper is to examine the accuracy of using the WF estimates of $\mathrm{ET}_{o}\left(\mathrm{ET}_{o}, \mathrm{WF}\right)$ for a non-synoptic location when compared with those obtained when the PMETo equation is used with observed weather data $\left(\mathrm{ET}_{o, \text { obs }}\right)$. The paper includes the calibration and validation of the model using observations of the soil water content, as well as the comparison of results of the same model when $\mathrm{ET}_{o, \mathrm{WF}}$ and $\mathrm{ET}_{o \text {,obs }}$ are used as model inputs. The application refers to various irrigation treatments of a wheat crop at Daxing, in the North China Plain.

\section{Material and methods}

\subsection{Reference ET estimations}

For the purpose of this study, two sets of weather data were used to estimate $\mathrm{ET}_{o}$ : one using hourly observations from a nearby weather station, which computed daily values are referred hereafter as $\mathrm{ET}_{o \text {, obs }}$; the other consisting of weather forecast messages from the public media, which estimated daily values are referred as $\mathrm{ET}_{o}, \mathrm{WF}$.

The daily $\mathrm{ET}_{o}\left(\mathrm{~mm} \mathrm{~d}^{-1}\right)$ was computed with the PM-ETo equation (Allen et al., 1998):

$\mathrm{ET}_{o}=\frac{0.408 \Delta\left(R_{n}-G\right)+\gamma \frac{900}{T+273} u_{2}\left(e_{s}-e_{a}\right)}{\Delta+\gamma\left(1+0.34 u_{2}\right)}$

where $R_{n}$ is the net radiation at the crop surface $\left(\mathrm{MJ} \mathrm{m}^{-2} \mathrm{~d}^{-1}\right), G$ is soil heat flux density $\left(\mathrm{MJ} \mathrm{m}^{-2} \mathrm{~d}^{-1}\right), T$ is the air temperature at $2 \mathrm{~m}$ height $\left({ }^{\circ} \mathrm{C}\right), u_{2}$ is the wind speed at $2 \mathrm{~m}$ height $\left(\mathrm{m} \mathrm{s}^{-1}\right), e_{s}$ is the vapour pressure of the air at saturation $(\mathrm{kPa}), e_{a}$ is the actual vapour pressure $(\mathrm{kPa}), \Delta$ is the slope of the vapour pressure curve $\left(\mathrm{kPa}^{\circ} \mathrm{C}^{-1}\right)$, and $\gamma$ is the psychrometric constant $\left(\mathrm{kPa}^{\circ} \mathrm{C}^{-1}\right) . G$ may be ignored for daily time step computations.

The $\mathrm{ET}_{o}$ estimation procedure using WF data (Cai et al., 2007) consists of estimating the parameters of Eq. (1) from the weather forecast messages using daily maximum and minimum air temperatures, wind grade and weather conditions (such as sunny, cloudy, rainy). The forecasted values of $T_{\max }$ and $T_{\min }\left({ }^{\circ} \mathrm{C}\right)$ are used similarly to the observed ones in $\mathrm{ET}_{o}$ computations. The daily actual vapour pressure $\left(e_{a}\right)$ is estimated from the forecasted daily $T_{\min }$ adopting the following equation (Allen et al, 1998):

$e_{a}=e^{0}\left(T_{\min }\right)=0.611 \exp \left[\frac{17.27 T_{\min }}{T_{\min }+237.3}\right]$

where $e_{a}$ is the actual vapour pressure $(\mathrm{kPa})$ and $e^{o}\left(T_{\min }\right)$ is the saturation vapour pressure at $T_{\min }$.

In the former study (Cai et al., 2007), the global radiation $R_{s}\left(\mathrm{MJ} \mathrm{m}^{-2} \mathrm{~d}^{-1}\right)$ was estimated from the forecasted "weather condition" referring to five cloudiness conditions: clear sky, clear to cloudy, cloudy, overcast and rainy. The actual duration of sunshine hours $\mathrm{n}$ was then estimated from the day time duration $N$ as $n=a N$, where the parameter $a$ assumed the values $0.9,0.7,0.5,0.3$ and 0.1 respectively for the five cloudiness conditions referred above. Then $R_{S}$ was computed with the Angström equation (Angström, 1924). However, considering the good results obtained for the estimation of $R_{S}$ from the difference $T_{\max }-T_{\min }$ (Liu and Pereira, 2001; Pereira et al., 2003a; Popova et al., 2006b; Jabloun and Sahli, 2008), the above mentioned procedure was replaced in this study by the Hargreaves' radiation equation modified by Allen et al. (1998):

$R_{s}=k_{R s}\left(T_{\max }-T_{\min }\right)^{0.5} R_{a}$

where $k_{R s}$ is the adjustment coefficient $\left({ }^{\circ} \mathrm{C}^{-0.5}\right)$, and $R_{a}$ is the radiation on top of the atmosphere $\left(\mathrm{MJ} \mathrm{m}^{-2} \mathrm{~d}^{-1}\right) . k_{R s}$ is empirical and differs for "interior" or "coastal" regions. For "interior" locations, where land mass dominates and air masses are not strongly influenced by a large water body, $k_{R s} \approx 0.17$. This value has been previously tested for the region (Pereira et al., 1998; Liu and Pereira, 2001; Pereira et al., 2003a). 
The daily wind speed $\left(u_{z}\right)$ at height $\mathrm{z}$ is obtained from the weather forecast messages of wind grade following the standards of meteorological observation (CMA, 2003) using a conversion table reported by Cai et al. (2007). The wind speed at $2 \mathrm{~m}$ height $\left(u_{2}\right)$ is then obtained from $u_{z}$ through the following equation:

$u_{2}=u_{z} \frac{4.87}{\ln (67.8 z-5.42)}$

where $u_{2}$ is the wind speed at $2 \mathrm{~m}$ height $\left(\mathrm{m} \mathrm{s}^{-1}\right), u_{z}$ is the measured wind speed at height $z\left(\mathrm{~m} \mathrm{~s}^{-1}\right)$, and $\mathrm{z}$ is the height of wind measurements above the ground surface $(\mathrm{m})$.

\subsection{Field experiments and data collection}

Field experiments with winter wheat (Triticum aestivum L.) were carried out at the Irrigation Experiment Station of the China Institute of Water Resources and Hydropower Research (IWHR) at Daxing, south of Beijing $\left(39^{\circ} 37^{\prime} \mathrm{N}\right.$ latitude, $116^{\circ} 26^{\prime} \mathrm{E}$ longitude and $40.1 \mathrm{~m}$ a.s.l. elevation). Wheat is the main irrigated crop in the region. The climate in the experimental site is semiarid to sub-humid, with cold and dry winter and hot and humid summer, when monsoon rains occur. Further information on the climate in the North China Plain is provided by Wang et al. (2008). An automatic weather station is installed in the experimental station, which provides for measurements of air temperature, relative humidity, global and net radiation, wind speed at $2 \mathrm{~m}$ height, soil temperature at various depths, and precipitation. The average values of main climatic variables for the period 19952005 are presented in Fig. 1 for the winter wheat growing season. The behaviour of main climate variables in the area is reported by Pereira et al. (1998, 2003a).

Soils in this area of the North China Plain are silty soils formed by deposits of the loess formations. It was observed that the soil hydraulic properties relevant for water balance studies vary little in the area (Ding, 1998; Liu and Pereira, 2003; Pereira et al., 1998, 2003a; Xu and Mermoud, 2003). The soil in the experimental area is a silt loam, with average field capacity $\left(\theta_{\mathrm{FC}}\right)$ and wilting point $\left(\theta_{\mathrm{WP}}\right)$ of 0.334 and $0.128 \mathrm{~m}^{3} \mathrm{~m}^{-3}$ in the crop root zone $\left(1 \mathrm{~m}\right.$ depth). $\theta_{\mathrm{FC}}$ and $\theta_{\mathrm{WP}}$ were measured in laboratory as the soil water content at respectively 33 and $1500 \mathrm{kPa}$ suction pressure. The main soil hydraulic properties are presented in Table 1. Soil salinity is not a problem in the area because the monsoon rains provide for natural leaching; however, the application of gypsum may be considered among the soil management practices desirable for the area (Ding, 1998; Pereira et al., 1998, 2003a).

The groundwater in North China Plain is over-exploited, including for irrigation purposes, causing large water table depletion when a succession of dry years occurs (e.g. Cai et al., 1996; Randin et al., 1999; Zhao et al., 2004; Nakayama et al., 2006). This problem led to develop studies in the area aimed at developing appropriate irrigation practices and
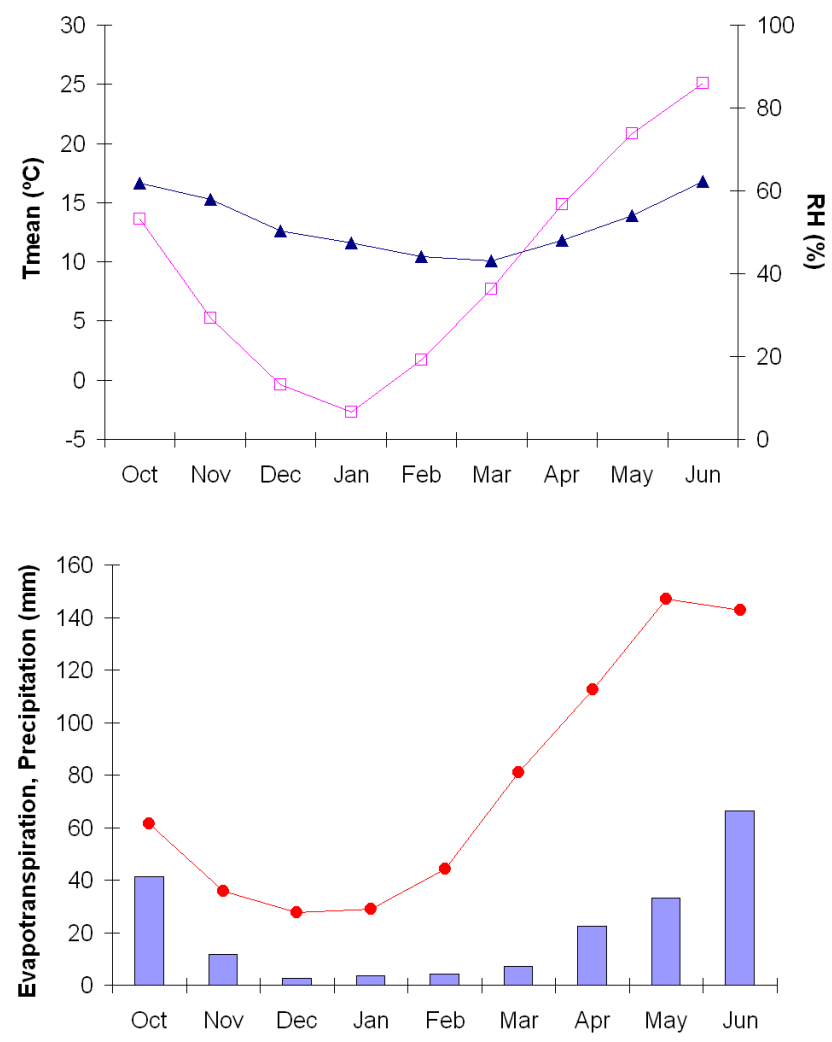

Fig. 1. Average weather characteristics of the winter wheat crop season at Daxing, 1995-2005: (a) monthly temperature ( $\square$ ) and relative humidity $(\mathbf{\Lambda})$; (b) monthly precipitation $(\mathbf{\square})$ and reference evapotranspiration, $\mathrm{ET}_{o}(\bullet)$.

demonstrations in farmers fields aimed at reducing the demand and controlling groundwater use (Pereira et al., 1998, 2003a). The experimental area is part of the network of experimentation developed to improve soil and water management, and regular observations of the groundwater table are performed. Information to farmers is provided by local extension officers. Observations at Daxing have shown that the groundwater table is there at a depth near $18 \mathrm{~m}$; therefore, capillary rise from the groundwater was not considered in the soil water balance calculations.

The experiments were developed during two winter wheat growing seasons, 2005-2006 and 2006-2007. Wheat is the main irrigated crop in the area; a few horticultural crops are also practiced but wheat is the one having by far the highest demand for water. Summer crops are irrigated only when the monsoon rains are scarce. The experiments were designed for both the evaluation of the performance of using $\mathrm{WF}$ data to compute $\mathrm{ET}_{o}$ and for agronomic assessment of irrigation scheduling and fertilization practices but results of agronomic nature are not analysed in this paper. The experiments were based upon results of former studies in the North China Plain aimed at developing water saving practices (e.g., Liu et al., 1998, 2004; Pereira et al., 1998, 2003a). Water 
Table 1. Main soil hydraulic properties for water balance purposes in Daxing experimental station.

\begin{tabular}{cccccc}
\hline Layer & $\begin{array}{c}\text { Depth } \\
(\mathrm{cm})\end{array}$ & $\begin{array}{c}\text { Bulk density } \\
\left(\mathrm{g} \mathrm{cm}^{-3}\right)\end{array}$ & $\begin{array}{c}\text { Saturated water content } \\
\left(\mathrm{m}^{3} \mathrm{~m}^{-3}\right)\end{array}$ & $\begin{array}{c}\text { Field capacity } \\
\left(\mathrm{m}^{3} \mathrm{~m}^{-3}\right)\end{array}$ & $\begin{array}{c}\text { Wilting point } \\
\left(\mathrm{m}^{3} \mathrm{~m}^{-3}\right)\end{array}$ \\
\hline 1 & $0 \sim 10$ & 1.30 & 0.46 & 0.32 & 0.09 \\
2 & $10 \sim 20$ & 1.46 & 0.46 & 0.34 & 0.13 \\
3 & $20 \sim 40$ & 1.48 & 0.47 & 0.35 & 0.10 \\
4 & $40 \sim 60$ & 1.43 & 0.45 & 0.33 & 0.11 \\
5 & $60 \sim 100$ & 1.39 & 0.44 & 0.31 & 0.16 \\
\hline
\end{tabular}
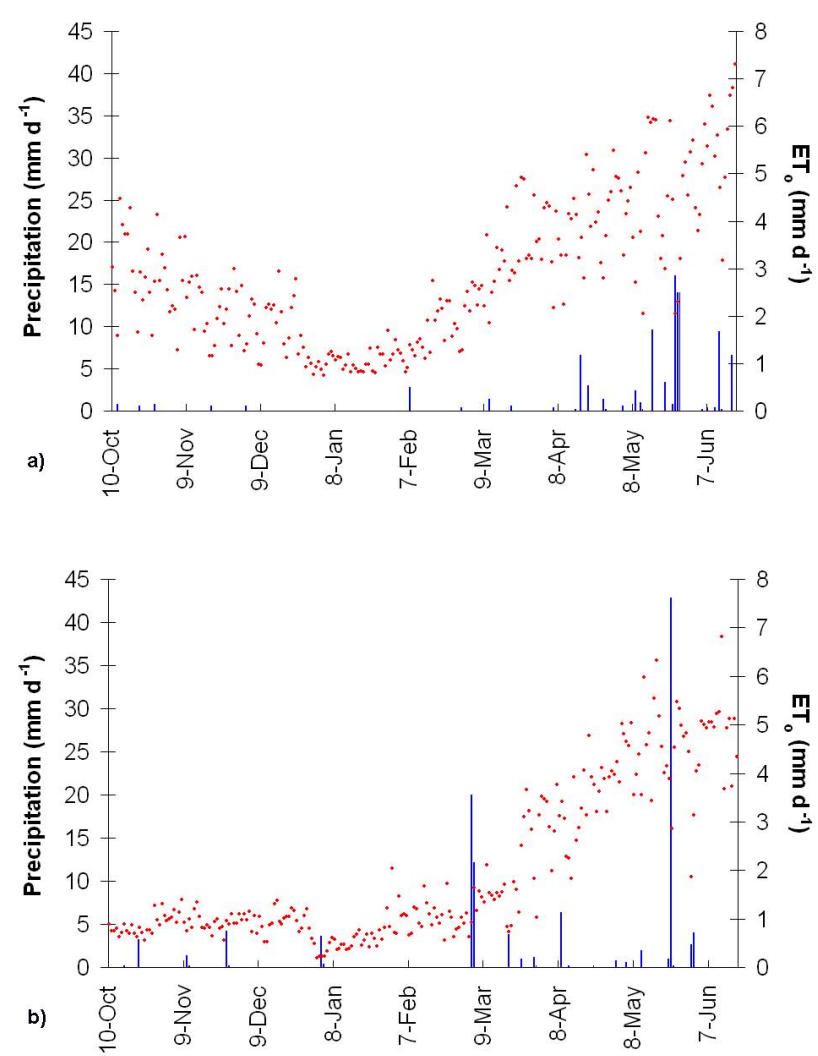

Fig. 2. Daily $\operatorname{ET}_{o}(\bullet)$ and precipitation $(\mid)$ during the wheat experiments: (a) 2005-2006; and (b) 2006-2007.

savings result from combining improved irrigation scheduling with the amelioration of the basin irrigation systems (Fernando et al., 1998; Liu et al., 2000, 2004; Liu and Pereira, 2003). Studies on basin irrigation practices (Bai et al., 2005) were developed in parallel with this research aiming at further developments in water saving irrigation.

The daily $\mathrm{ET}_{o}$ and precipitation for both seasons are shown in Fig. 2. The wheat crop season developed from 10 October to 18 June for both years. The total precipitation was $99.6 \mathrm{~mm}$ for 2005-2006 and $112.6 \mathrm{~mm}$ for 2006-2007; in this season there were less rainfall events than for the previous one. There were no noticeable differences in season $\mathrm{ET}_{o}$.
The experiments were performed using a randomized block design with three or more plots per treatment. Every plot was $5.5 \times 5.5 \mathrm{~m}$ in a N-S row direction. There were four irrigation treatments for 2005-2006 (W1 to W4) and five for 2006-2007 (T1 to T5). All irrigation treatments were performed with basin irrigation and conventional tillage. All treatments received a winter irrigation that refilled the soil reservoir to field capacity. The irrigation treatments were different in both years due to different agronomic objectives including the application of a light irrigation by early spring aimed at fertigation in the second year. The application depths are given in Table 2 and the criteria for the irrigation timings are described as follows:

W1 - rain fed from the winter to harvesting;

W2 - mild water stress, with a soil water threshold equal to $60 \%$ of $\theta_{\mathrm{FC}}$;

W3 - mild water stress with a soil water threshold equal to $60 \%$ of $\theta_{\mathrm{FC}}$, with smaller water depths than $\mathrm{W} 2$;

W4 - irrigation timings and depths as recommended by the farmer' adviser for water saving;

T1 - no water stress with a soil water threshold equal to $80 \%$ of $\theta_{\mathrm{FC}}$;

T2 - no water stress with a soil water threshold equal to $70 \%$ of $\theta_{\mathrm{FC}}$;

T3 - mild water stress with a soil water threshold equal to $60 \%$ of $\theta_{\mathrm{FC}}$;

T4 - mild water stress at the late stages of the crop, when the soil water threshold was equal to $60 \%$ of $\theta_{\mathrm{FC}}$;

T5 - irrigation timings and depths as recommended by the farmer' adviser for water saving.

The soil water content was measured every 4 days in each plot with two replicates using a time-domain reflectometry (TDR) system TRIME ${ }^{\circledR}$-T3/IPH from 0.2 to $1.2 \mathrm{~m}$ depth with observations every $0.2 \mathrm{~m}$. The TDR measuring accuracy is $2 \%$. For the surface layer, soil samples were taken to be dried in the oven. Crop heights were observed every ten 
Table 2. Irrigation treatments: applied water depths and dates.

\begin{tabular}{|c|c|c|c|c|c|}
\hline Crop season & Treatment & Initial stage (winter irrigation) & Development stage & Mid-season Stage & Late stage \\
\hline \multirow[t]{4}{*}{ 2005-2006 } & W1 & $90 \mathrm{~mm}(20 / 11)$ & & & \\
\hline & W2 & $90 \mathrm{~mm}(20 / 11)$ & $90 \mathrm{~mm}(05 / 04)$ & $80 \mathrm{~mm}(12 / 5)$ & \\
\hline & W3 & $90 \mathrm{~mm}(20 / 11)$ & $65 \mathrm{~mm}(05 / 04)$ & $80 \mathrm{~mm}(05 / 05)$ & \\
\hline & W4 & $90 \mathrm{~mm}(20 / 11)$ & $115 \mathrm{~mm}(05 / 04)$ & $115 \mathrm{~mm}(12 / 05)$ & \\
\hline \multirow[t]{5}{*}{ 2006-2007 } & $\mathrm{T} 1$ & $90 \mathrm{~mm}(18 / 11)$ & $30 \mathrm{~mm}(06 / 04)^{*}$ & $60 \mathrm{~mm}(21 / 04), 63 \mathrm{~mm}(07 / 05)$ & $67 \mathrm{~mm}(04 / 06)$ \\
\hline & $\mathrm{T} 2$ & $90 \mathrm{~mm}(18 / 11)$ & $30 \mathrm{~mm}(06 / 04)^{*}$ & $97 \mathrm{~mm}(30 / 04), 84 \mathrm{~mm}(14 / 05)$ & \\
\hline & T3 & $90 \mathrm{~mm}(18 / 11)$ & $30 \mathrm{~mm}(06 / 04)^{*}$ & $102 \mathrm{~mm}(07 / 05)$ & \\
\hline & $\mathrm{T} 4$ & $90 \mathrm{~mm}(18 / 11)$ & $30 \mathrm{~mm}(06 / 04)^{*}$ & $65 \mathrm{~mm}(26 / 04)$ & $86 \mathrm{~mm}(04 / 06)$ \\
\hline & T5 & $90 \mathrm{~mm}(18 / 11)$ & $30 \mathrm{~mm}(06 / 04)^{*}$ & $96 \mathrm{~mm}(07 / 05)$ & $70 \mathrm{~mm}(04 / 06)$ \\
\hline
\end{tabular}

Note: Numbers in brackets refer to the day and month of the irrigation event.

* Fertilizers were applied with this irrigation event.

days. Yields and yield components were observed at harvesting. Field measurements were performed only after the soil defrosts, when the crop has started growing by the end of the winter. The water was conveyed to the fields by a PVC pipe from the well pump where discharge was measured with a flowmeter. Water applications were controlled by an automated low pressure valve.

Weather data were collected every $30 \mathrm{~min}$ and integrated to the hour. These hourly values were used to compute the $\mathrm{ET}_{o \text {,obs }}$ adopting the procedures described by Allen et al. $(1998,2006)$. The $\mathrm{ET}_{o, \mathrm{WF}}$ was computed daily from the weather forecast messages available from the Beijing Daily Newspaper acceded through the web. This allowed adopting automatic digital processing of those messages to compute $\mathrm{ET}_{o, \mathrm{WF}}$.

\subsection{Simulation of the soil water balance}

The ISAREG model (Teixeira and Pereira, 1992) was used to simulate the soil water balance for all treatments using both $\mathrm{ET}_{o, \mathrm{obs}}$ and $\mathrm{ET}_{o, \mathrm{WF}}$ as inputs, which allowed assessing the accuracy of $\mathrm{ET}_{o, \mathrm{WF}}$ as input for modelling. ISAREG is an irrigation scheduling simulation model that performs the soil water balance at the field scale. The model is described in detail by Teixeira and Pereira (1992), Liu et al. (1998) and Pereira et al. (2003b), the latter referring to the Windows version of the model. The water balance model ISAREG was selected after comparing its results with those from the water flux model WAVE (Vanclooster et al., 1995) for irrigation scheduling purposes and considering that data requirements for water balance simulations are much less than for flux simulations (Pereira et al., 1998). However, because WAVE accurately computed capillary rise and percolation, it was used to support developing a set of parametric equations for estimating these variables with ISAREG (Liu et al., 2006).

The water balance is performed for various time-step computations depending on weather data availability. The model is used for a variety of crops and environments, e.g. in the
Mediterranean region (Oweis et al., 2003; Zairi et al., 2003), North China (Liu et al., 1998, 2006; Pereira et al., 2007), South America (Victoria et al., 2005), Central Asia (Fortes et al., 2005; Cholpankulov et al., 2008) and Europe (Popova et al., 2006a; Cancela et al., 2006). The model performs the irrigation scheduling simulations according to the following user-defined options:

- to define an irrigation scheduling to maximize crop yields, i.e. without crop water stress;

- to generate an irrigation scheduling using selected irrigation thresholds, including for an allowed water stress, and responding to water availability restrictions imposed at given time periods;

- to evaluate yield and water use impacts of a given irrigation schedule;

- to test the model performance against observed soil water data and using actual irrigation dates and depths, which is the option used for calibration and validation in this study;

- to execute the water balance without irrigation; and

- to compute the net crop irrigation requirements, and performing the respective analysis of frequencies when a weather data series is considered.

The model input data for a daily time step computation includes:

1. Meteorological data concerning precipitation, $P$ $\left(\mathrm{mm} \mathrm{d}^{-1}\right)$ and reference evapotranspiration, $\mathrm{ET}_{o}$ $\left(\mathrm{mm} \mathrm{d}^{-1}\right)$, or daily weather data to compute $\mathrm{ET}_{o}$ with the FAO-PM methodology, including alternative computation methods for missing climate data as for this study (Allen et al., 1998; Popova et al., 2006b); 
2. Soil data for a multi-layer soil relative to each layer, the respective depth $d(\mathrm{~m})$; the soil water content at field capacity $\theta_{\mathrm{FC}}\left(\mathrm{m}^{3} \mathrm{~m}^{-3}\right)$ and the wilting point $\theta_{\mathrm{WP}}\left(\mathrm{m}^{3} \mathrm{~m}^{-3}\right)$, and the initial soil water content $\theta_{\text {in }}$ $\left(\mathrm{m}^{3} \mathrm{~m}^{-3}\right)$ in the soil profile; additional data not used in this study refer to the parameters for the equations relative to groundwater contribution, percolation; and soil salinity.

3. Crop data referring to dates of crop development stages, crop coefficients, $K_{c}$ (non dimensional); root zone depths $Z_{r}(\mathrm{~m})$; soil water depletion fractions for nostress, $p$ (non dimensional); crop height $h(\mathrm{~m})$. Inputs not used in this study refer to the seasonal water-yield response factor, $K_{y}$ (non dimensional); and to parameters characterizing the soil salinity impacts on yields (Pereira et al., 2007);

The crop coefficients, root depths and soil water depletion fractions for no stress refer to four crop development periods: initial (which comprises a period when the soil is frozen), crop development, mid season and end season. The crop coefficients express the relationship between $\mathrm{ET}_{c}$ and $\mathrm{ET}_{o}$; when using tabled values for $K_{c}$ these are corrected for climate as a function of the minimum relative humidity, wind speed and crop height (Allen et al., 1998). The soil water depletion fractions for no stress ( $p$, non-dimensional) refer to the soil water that can be extracted without impacting the crop yields; when that fraction is exceeded the actual crop $\mathrm{ET}\left(\mathrm{ET}_{a}\right)$ becomes smaller that the potential or maximum crop ET $\left(\mathrm{ET}_{m}, \mathrm{~mm} \mathrm{~d}^{-1}\right)$.

As described by Liu et al. (1998), the maximum available soil water in the root zone (mm) is $R_{\max }=\mathrm{TAW}$, with

$$
\mathrm{TAW}=1000\left(\theta_{\mathrm{FC}}-\theta_{\mathrm{WP}}\right) Z_{r}
$$

where TAW is the total available soil water $(\mathrm{mm}), \theta_{\mathrm{FC}}$ is the soil water content at field capacity $\left(\mathrm{m}^{3} \mathrm{~m}^{-3}\right), \theta_{\mathrm{WP}}$ is the soil water content at the wilting point $\left(\mathrm{m}^{3} \mathrm{~m}^{-3}\right)$, and $Z_{r}$ is the root zone depth (m).

The soil water threshold for non-stress corresponds to the minimum available soil water in the root zone that permits crop evapotranspiration without causing crop water stress, i.e. when the soil water extracted by the crop and soil evaporation does not exceed the soil water depletion fraction for no stress $p$. The available soil water is then $R_{p}=\mathrm{RAW}$, with

$\mathrm{RAW}=p \mathrm{TAW}=p 1000\left(\theta_{\mathrm{FC}}-\theta_{\mathrm{WP}}\right) Z_{r}$

where RAW is the readily available soil water $(\mathrm{mm})$.

When the available soil water $R \geq R_{p}$, the actual crop evapotranspiration equals the maximum evapotranspiration $\mathrm{ET}_{m}$ $\left(\mathrm{mm} \mathrm{d}^{-1}\right)$ :

$\mathrm{ET}_{m}=K_{c} \mathrm{ET}_{o}$ where $K_{c}$ is the crop coefficient and $\mathrm{ET}_{o}$ is the reference evapotranspiration $\left(\mathrm{mm} \mathrm{d}^{-1}\right)$. Then, between two irrigation events, $R$ varies linearly with the time $t$ as

$R_{t}=R_{o}+\left(W_{i n}-\mathrm{ET}_{m}\right) t$

where $R_{o}$ is the initial value of $R$ in the considered time pe$\operatorname{riod}(\mathrm{mm})$, and $W_{\text {in }}$ is the water input to the root zone storage $(\mathrm{mm})$ due to precipitation and capillary rise. A daily time step computation is used.

When $R<R_{p}$ the water available in the soil is insufficient to keep crop evapotranspiration at its potential, thus $\mathrm{ET}_{a}<\mathrm{ET}_{m}$. It is assumed that $\mathrm{ET}_{a}\left(\mathrm{~mm} \mathrm{~d}^{-1}\right)$ decreases with the available soil water $R$ as:

$\mathrm{ET}_{a}=\frac{\mathrm{ET}_{m}}{R_{p}} R$

with $R$ decreasing non-linearly with the time.

$R_{t}=\frac{W_{i n}}{\alpha}\left(R_{o}-\frac{W_{i n}}{\alpha}\right) e^{-\alpha t}$

where $\alpha=\mathrm{ET}_{m} / R_{p}$ (further information in Teixeira and Pereira, 1992; and Liu et al., 1998).

The soil water balance is performed in ISAREG with a daily time step as:

$\mathrm{SW}_{i}=\mathrm{SW}_{i-1}+P_{e, i}+I_{i}+G_{c, i}-\mathrm{ET}_{a, i}-D_{r, i}$

where $\mathrm{SW}_{i}$ and $\mathrm{SW}_{i-1}$ are respectively the soil water storage $(\mathrm{mm})$ in the crop root zone at the end of day $i$ and of the previous day, $i-1 ; P_{i}$ is the precipitation; $I_{i}$ is the net irrigation depth; $G_{c, i}$ is the capillary rise; $\mathrm{ET}_{a, i}$ is the actual crop evapotranspiration, and $D_{r, i}$ is the deep percolation out of the root zone, all referring to day $i$. All units but for SW are in $\mathrm{mm} \mathrm{d}^{-1} . G_{c, i}$ was neglected in this application as referred before. $D_{r, i}$ was computed using a decay function (Liu et al., 2006).

\subsection{Indicators to assess the accuracy of $\mathrm{ET}_{o}$ estimates and model simulations}

$\mathrm{ET}_{o}$ estimates with observed and forecasted weather data, respectively $\mathrm{ET}_{o, \text { obs }}$ and $\mathrm{ET}_{o, \mathrm{WF}}$, were compared and the accuracy of WF predictions were evaluated through selected statistical indicators: the root mean square error, the relative error, the Willmott index of agreement, and the modelling efficiency, as well as the linear regression forced to the origin. The same indicators were used to evaluate the accuracy of model predictions of the soil water content compared with the soil water observations relative to the treatments referred above. This evaluation was performed for both the model calibration and validation and for model testing when $\mathrm{ET}_{o}$,WF was used. The mentioned statistical indicators (Loague and Green, 1991; Legates and MacCabe, 1999; Cholpankulov et al., 2008) are defined as follows:

- Coefficient of regression, $b$ (when the regression is forced to the origin): 
$b=\frac{\sum_{i=1}^{m} O_{i} \times P_{i}}{\sum_{i=1}^{m} O_{i}^{2}}$

- Coefficient of determination, $R^{2}$ :

$R^{2}=\left\{\frac{\sum_{i=1}^{m}\left(O_{i}-\bar{O}\right)(P i-\bar{P})}{\left[\sum_{i=1}^{m}\left(O_{i}-\bar{O}\right)^{2}\right]^{0.5}\left[\sum_{i=1}^{m}\left(P_{i}-\bar{P}\right)^{2}\right]^{0.5}}\right\}^{2}$

- Root Mean Square Error, RMSE:

$\mathrm{RMSE}=\left[\frac{\sum_{i=1}^{m}\left(P_{i}-O_{i}\right)^{2}}{m}\right]^{0.5}$

- Relative Error, RE:

$\mathrm{RE}=\frac{\mathrm{RMSE}}{\bar{O}}$

- Modelling efficiency, EF:

$\mathrm{EF}=1.0-\frac{\sum_{i=1}^{m}\left(O_{i}-P_{i}\right)^{2}}{\sum_{i=1}^{m}\left(O_{i}-\bar{O}\right)^{2}}$

- The Willmott index of agreement, $d$ :

$d=1-\frac{\sum_{i=1}^{m}\left(O_{i}-P_{i}\right)^{2}}{\sum_{i=1}^{m}\left(\left|P_{i}-\bar{O}\right|+\left|O_{i}-\bar{O}\right|\right)^{2}}$

where the $m$ is the number of observations, $O_{i}$ and $P_{i}$ are respectively the $i$-th observed and predicted data; $\bar{O}$ is the average value for $O_{i}$ with $i=1,2, \ldots, m, \bar{P}$ is the average of the data arrays of $P_{i}$. The values of EF and $d$ vary from 0 to 1.0 according to the quality of model fitting and are desirably close to 1.0. The estimation error indicators RE and RMSE are hoped to be as small as possible. The coefficient $b$ may be larger or smaller than 1.0 when there is respectively overestimation or underestimation of the target variable. When $R^{2}$ is close to 1.0 the variance of the estimation errors is small.

\section{Results and discussion}

\subsection{Comparing $\mathbf{E T}_{o}$ estimates obtained from observed and forecast messages weather data}

As analysed by Cai et al. (2007), the weather forecasted data do not exactly match those observed and lead to over- or
Table 3. Statistical indicators comparing $\mathrm{ET}_{o}$ computations using fully observed data sets $\left(\mathrm{ET}_{o, \text { obs }}\right)$ and weather forecasted data $\left(\mathrm{ET}_{o, \mathrm{WF}}\right)$ for two wheat crop seasons.

\begin{tabular}{ccccccc}
\hline & $b$ & $R^{2}$ & $\begin{array}{c}\text { RMSE } \\
\left(\mathrm{mm} \mathrm{d}^{-1}\right)\end{array}$ & RE & EF & $d$ \\
\hline $2005-2006$ & 0.878 & 0.834 & 0.764 & 0.272 & 0.746 & 0.939 \\
$2006-2007$ & 1.163 & 0.850 & 0.771 & 0.389 & 0.767 & 0.945 \\
\hline
\end{tabular}

underestimation of the climatic parameters of the PenmanMonteith reference evapotranspiration and respective results. Figure 3 compares the daily values of $\mathrm{ET}_{o}$ computed with observed weather data $\left(\mathrm{ET}_{o, \mathrm{obs}}\right)$ and with WF data $\left(\mathrm{ET}_{o, \mathrm{WF}}\right)$. Considering the regression forced to the origin when comparing both sets of daily $\mathrm{ET}_{o}$ values it may be observed that $\mathrm{ET}_{o}$, WF is underestimated in relation to $\mathrm{ET}_{o, \text { obs }}$ for the wheat crop season 2005-2006, while it is overestimated for 20062007 The regression coefficients are respectively 0.88 and 1.16 , and the corresponding $R^{2}$ values are high, respectively 0.83 and 0.85 . Results in Table 3 show that the RMSE values are relatively small: 0.76 and $0.77 \mathrm{~mm} \mathrm{~d}^{-1}$ for the 20052006 and 2006-2007 crop seasons, respectively. These errors are similar to those observed earlier in North China when estimating $\mathrm{ET}_{o}$ from maximum and minimum temperature (Pereira et al., 2003a), and those observed by Popova et al. (2006b) for South Bulgaria when performing the same type of $\mathrm{ET}_{o}$ estimation. However, those errors are near to the upper range of those referred by Cai et al. (2007) for estimating $\mathrm{ET}_{o}$ from WF at eight locations in China. The relative errors are 0.27 and 0.39 for the two seasons considered (Table 3), which are larger than those computed for the eight locations. These RE values decrease to 0.18 and 0.25 when only the data relative to the period of simulation are considered, i.e., after crop reviving until harvesting, because the $\mathrm{ET}_{o}$ values are then larger than those for the autumn and winter period, thus impacts of inaccuracy in weather forecasting result then relatively less important. The values for the index $d$ are high (0.94 and 0.95) and the modelling efficiency $\mathrm{EF}$ is also high, with values 0.75 and 0.77 respectively for 2005-2006 and 2006-2007.

The smaller accuracy of estimation relatively to the former study performed for synoptic stations (Cai et al., 2007) was expected. The synoptic stations are explored by the China Meteorological Administration (CMA) and provide information on conditions of the atmosphere or weather as they exist simultaneously over a broad area and where observations are made at periodic times (usually at 3-hourly and 6-hourly intervals specified by the World Meteorological Organization), These observations are used to provide information for the global and regional circulation models used for the weather forecasts at the same locations. Therefore, when 

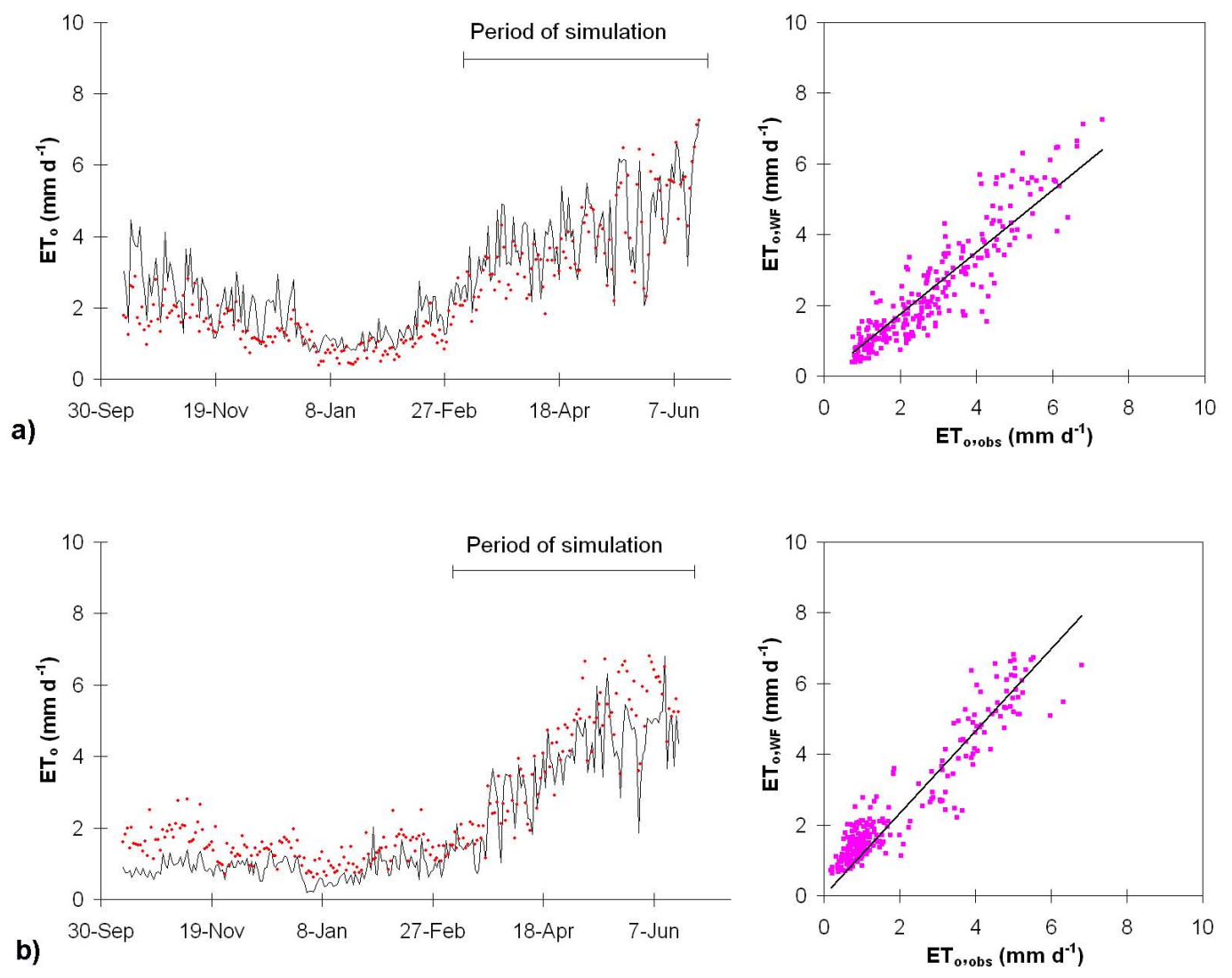

Fig. 3. Comparison of the $\mathrm{ET}_{o}$ values computed from observed and weather forecast messages data for the wheat crop season (a) for 20052006 and (b) for 2006-2007. On the left, the daily course of $\mathrm{ET}_{o, \text { obs }}$, (一) and $\mathrm{ET}_{o, \mathrm{WF}}(\bullet)$ from planting (October) to harvesting (June); on the right, the respective regression forced to the origin.

extrapolating these forecasts for non-synoptic weather stations, as in this study, it is expected that the forecasts will over- or under-predict the weather variables relatively to observations at the same locations. The fact that in the first season there was an over-prediction of $\mathrm{ET}_{o}$ and in the second $\mathrm{ET}_{o}$ was under-predicted may indicate that there is not a systematic error of prediction.

Overall, the results obtained indicate that estimating daily $\mathrm{ET}_{o}$ from weather forecast messages is feasible for locations out of the network of CMA synoptic weather stations despite the forecasting accuracy is smaller than for synoptic stations. This fact justifies the need to assess the impacts of using $\mathrm{ET}_{o}$,WF estimates instead of $\mathrm{ET}_{o \text {,obs }}$ when performing the soil water balance for irrigation scheduling, whose results are analysed below. Results indicate the need to further study the spatial variation of $\mathrm{ET}_{o}, \mathrm{WF}_{\text {F }}$ estimates when using them for providing real-time irrigation scheduling advising at project, basin or regional level.

\subsection{Model calibration and validation}

The calibration and validation of the model ISAREG was performed using $\mathrm{ET}_{o \text {, obs }}$ data. Irrigation treatments data for
Table 4. Wheat crop coefficients $K_{c}$ and depletion fractions for no stress $p$ obtained from model calibration in the crop season of 2005-2006.

\begin{tabular}{llll}
\hline Crop growth stages & Dates 1 & $K_{c}$ & $p$ \\
\hline Crop development & $(01 / 03 \sim 20 / 04)$ & $0.40-1.00$ & $0.60-0.50$ \\
Mid-season & $(21 / 04 \sim 31 / 05)$ & 1.00 & 0.50 \\
End season & $(01 / 06 \sim 18 / 06)$ & $1.00-0.30$ & $0.50-0.60$ \\
\hline
\end{tabular}

${ }^{1}$ Numbers in brackets refer to the day and month respectively.

2005-2006 were used for the calibration and those of 20062007 were used for validation. The calibration led to appropriate values for the crop coefficients $K_{c}$ and the depletion fractions $p$, which are given in Table 4 . The calibration was performed iteratively until the simulated soil water content matches the observed one. Initial values for the crop parameters were those tabled by Allen et al. (1998) after being corrected for climate as suggested by these authors. The simulations concern the period after soil defrost or crop reviving, i.e. the crop development, mid season and late season stages. 
Table 5. Statistical indicators for model goodness of fitting when comparing the soil water content observed and predicted by the model for the treatments used for calibration and validation.

\begin{tabular}{ccccccc}
\hline & $b$ & $R^{2}$ & $\begin{array}{c}\text { RMSE } \\
\left(\mathrm{m}^{3} \mathrm{~m}^{-3}\right)\end{array}$ & RE & EF & $d$ \\
\multicolumn{2}{c}{ Calibration (2005-2006) } \\
W1 & 0.98 & 0.85 & 0.007 & 0.035 & 0.69 & 0.94 \\
W2 & 0.98 & 0.92 & 0.008 & 0.035 & 0.89 & 0.97 \\
W3 & 0.99 & 0.89 & 0.006 & 0.027 & 0.88 & 0.97 \\
W4 & 1.02 & 0.96 & 0.006 & 0.024 & 0.97 & 0.99 \\
\hline All treatments & 0.99 & 0.97 & 0.007 & 0.030 & 0.96 & 0.99 \\
\hline \multicolumn{2}{l}{ Validation (2006-2007) } & & & & & \\
T1 & 1.02 & 0.75 & 0.009 & 0.030 & 0.77 & 0.93 \\
T2 & 1.02 & 0.62 & 0.003 & 0.010 & 0.66 & 0.90 \\
T3 & 1.00 & 0.88 & 0.008 & 0.028 & 0.92 & 0.98 \\
T4 & 1.02 & 0.93 & 0.010 & 0.037 & 0.92 & 0.98 \\
T5 & 1.01 & 0.87 & 0.010 & 0.034 & 0.89 & 0.97 \\
\hline All treatments & 1.01 & 0.92 & 0.010 & 0.034 & 0.88 & 0.97 \\
\hline
\end{tabular}

Results comparing the soil water content observed and simulated for the calibration are shown in Fig. 4 for two treatments (W2 and W4) and in Fig. 5a for all treatments W1 to W4. Moreover, because a rainfed treatment (W1) is included, the calibration was performed for the full range of soil water content values expected in the practice. The statistical indicators for the goodness of model fitting are presented in Table 5. For the four treatments, the coefficient of regression range 0.98 to 1.02 , thus very close to the target 1.0 value. The determination coefficients are quite high, ranging 0.85 to 0.96 . The estimation errors are small, with RMSE varying in a very short range ( 0.006 to $0.008 \mathrm{~m}^{3} \mathrm{~m}^{-3}$ ); RE values are also small, ranging from 0.024 to 0.035 . The values for $d$ and EF show that model fitting is good, with $d$ ranging 0.94 to 0.99 and EF varying from 0.69 to 0.97 . These results show that the simulated soil water content matches well with the observed values, i.e., the model accurately simulates the soil water balance of the wheat crop when the calibrated parameters are used.

The results for the validation with field data from the treatments of 2006-2007 are similar to those obtained for the calibration. Figure 4 shows the observed and simulated soil water for treatments $\mathrm{T} 3$ and T4, and in Fig. 5b results are shown for all treatments $\mathrm{T} 1$ to T5. The statistical indicators for goodness of model predictions are presented in Table 5. The $b$ values are just slightly higher than those for the calibration, and $R^{2}$ range from 0.62 to 0.93 . The estimations errors are also slightly higher than for the calibration, with $\mathrm{RMSE}=0.010 \mathrm{~m}^{3} \mathrm{~m}^{-3}$ and $\mathrm{RE}=0.034$ when all treatments are considered. The $d$ and $\mathrm{EF}$ indices are consequently slightly smaller than those for the calibration, with $d$ ranging 0.90 to 0.98 and EF ranging 0.66 to 0.92 . These results indicate that the parameters obtained at calibration are appropriate for the model simulations aimed at irrigation scheduling.
Table 6. Statistical indicators for model goodness of fitting when comparing the soil water content observed and predicted by the model $\mathrm{f}$ when $\mathrm{ET}_{o}$ was estimated from weather forecast messages $\left(\mathrm{ET}_{o, \mathrm{WF}}\right)$.

\begin{tabular}{ccccccc}
\hline & $b$ & $R^{2}$ & $\begin{array}{c}\text { RMSE } \\
\left(\mathrm{m}^{3} \mathrm{~m}^{-3}\right)\end{array}$ & RE & EF & $d$ \\
\hline 2005-2006 & & & & & & \\
W1 & 1.01 & 0.78 & 0.007 & 0.037 & 0.64 & 0.93 \\
W2 & 1.02 & 0.92 & 0.010 & 0.039 & 0.87 & 0.97 \\
W3 & 1.04 & 0.83 & 0.012 & 0.052 & 0.55 & 0.89 \\
W4 & 1.00 & 0.97 & 0.009 & 0.035 & 0.93 & 0.98 \\
\hline All treatments & 1.03 & 0.95 & 0.010 & 0.041 & 0.92 & 0.98 \\
\hline 2006-2007 & & & & & & \\
T1 & 0.98 & 0.74 & 0.012 & 0.041 & 0.57 & 0.90 \\
T2 & 1.00 & 0.78 & 0.009 & 0.031 & 0.78 & 0.94 \\
T3 & 0.96 & 0.84 & 0.016 & 0.057 & 0.69 & 0.93 \\
T4 & 0.99 & 0.93 & 0.010 & 0.037 & 0.92 & 0.98 \\
T5 & 0.98 & 0.80 & 0.013 & 0.046 & 0.80 & 0.94 \\
\hline All treatments & 0.99 & 0.82 & 0.012 & 0.043 & 0.81 & 0.95 \\
\hline
\end{tabular}

Considering both the calibration and validation results, it was verified that errors are smaller than those observed in former studies (Liu et al., 1998). It was also observed that the irrigation schedules adopted for water saving (W4 and T5) effectively respond to this objective and provided for water productivities among the highest in both years. It can be concluded that the model performed very well to predict the soil water content of the wheat crop during the development, mid-season and end-season crop stages.

\subsection{Accuracy of model predictions when $\mathrm{ET}_{o}$ is esti- mated from weather forecast messages}

All treatments were simulated with the model using the calibrated crop parameters given in Table 4 and adopting as model input the WF estimated $\mathrm{ET}_{o, \mathrm{WF}}$ instead of $\mathrm{ET}_{o \text {, obs }}$. The initial soil water content values used for these simulations are the same as for the calibration and validation. Results for the goodness of model predictions of the soil water content are given in Table 6. Selected simulation results for the treatments W2 and W4 in 2006, and T3 and T4 in 2007 are shown in Fig. 6. Results for all treatments and both crop seasons are presented in Fig. 7. As noted above, since treatments include rainfed and no water stress ones, the soil water content observations cover the full range of values expected in the practice.

The coefficients of regression are close to 1.0 (Table 6), ranging 1.0 to 1.04 for 2006 and from 0.96 to 1.0 in 2007 , i.e., there is a slight overestimation of the soil water content in 2006 when $\mathrm{ET}_{o}$, was underestimated, and underestimation in 2007 when $\mathrm{ET}_{o}$, was overestimated. However, the under- and over-estimation resulting for the prediction of the soil water 


\section{Calibration}
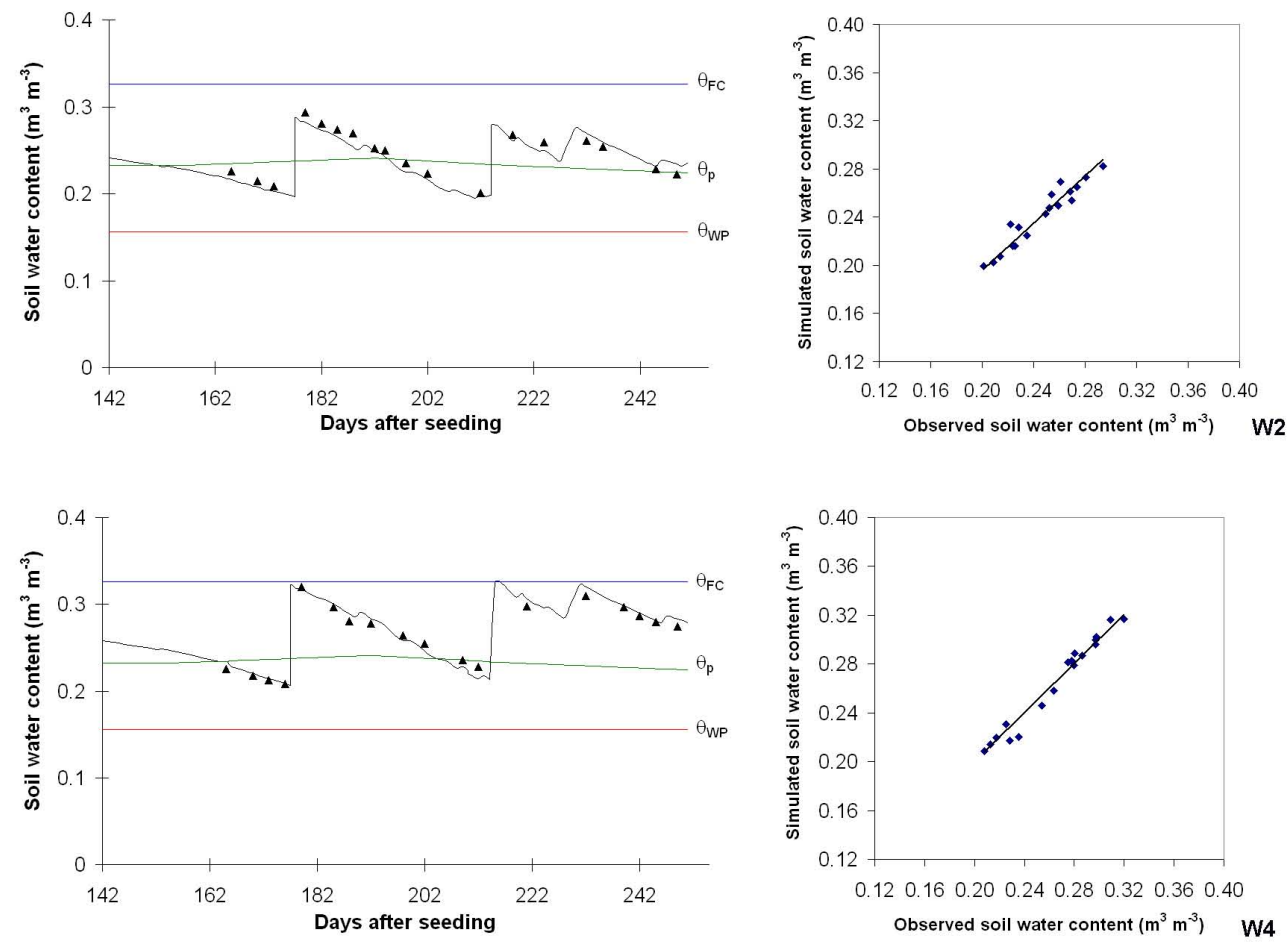

\section{Validation}
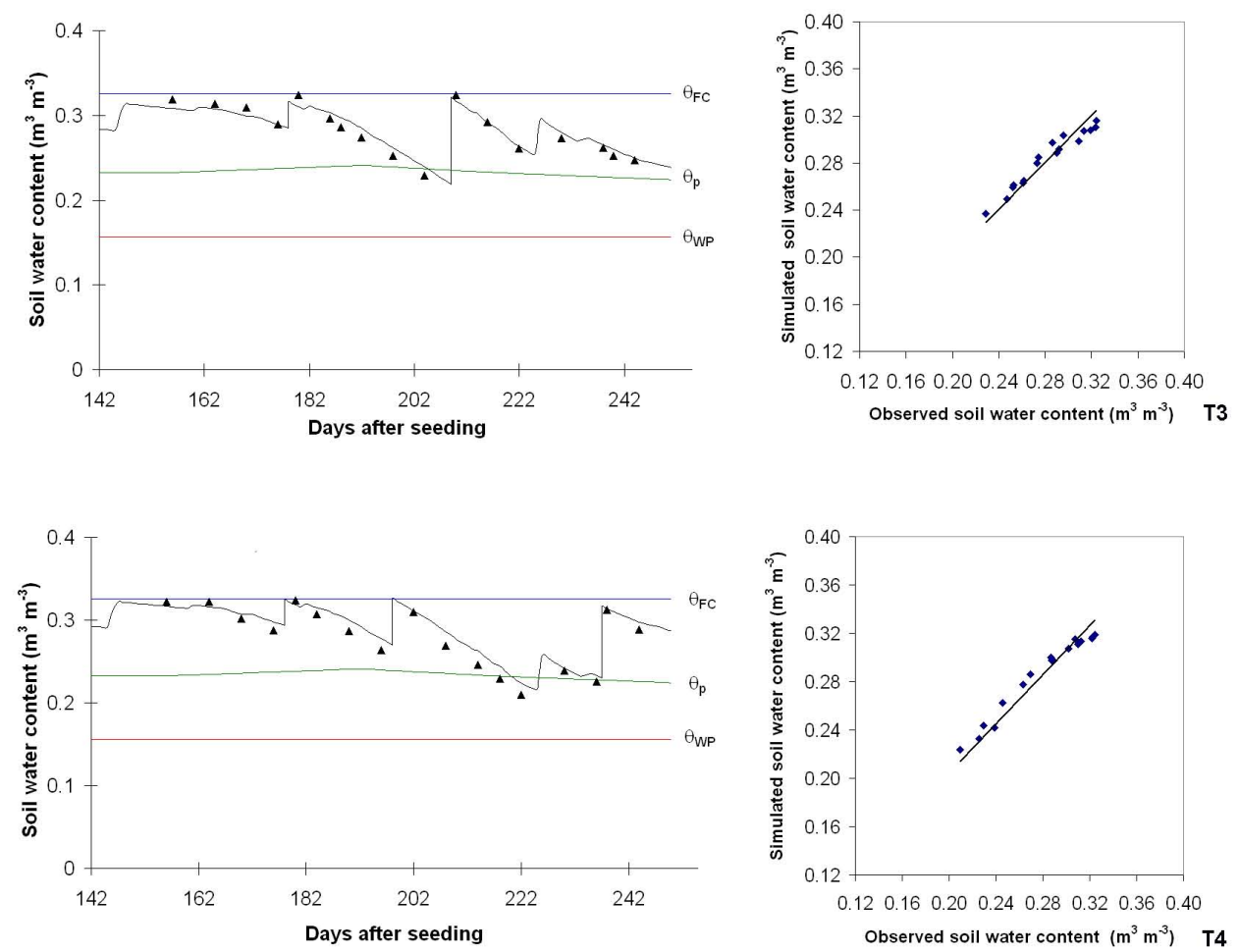

Fig. 4. Comparing the soil water content observed and predicted by the model for two calibration treatments (W2 and W4) and two validation treatments (T3 and T4). On the left: the daily course of the soil water; on the right, the respective regressions forced to the origin. The lines of $\theta_{\mathrm{FC}}, \theta_{p}$ and $\theta_{\mathrm{WP}}$ refer to the soil water content at field capacity, at the depletion fraction for no stress and at the wilting point, respectively. 

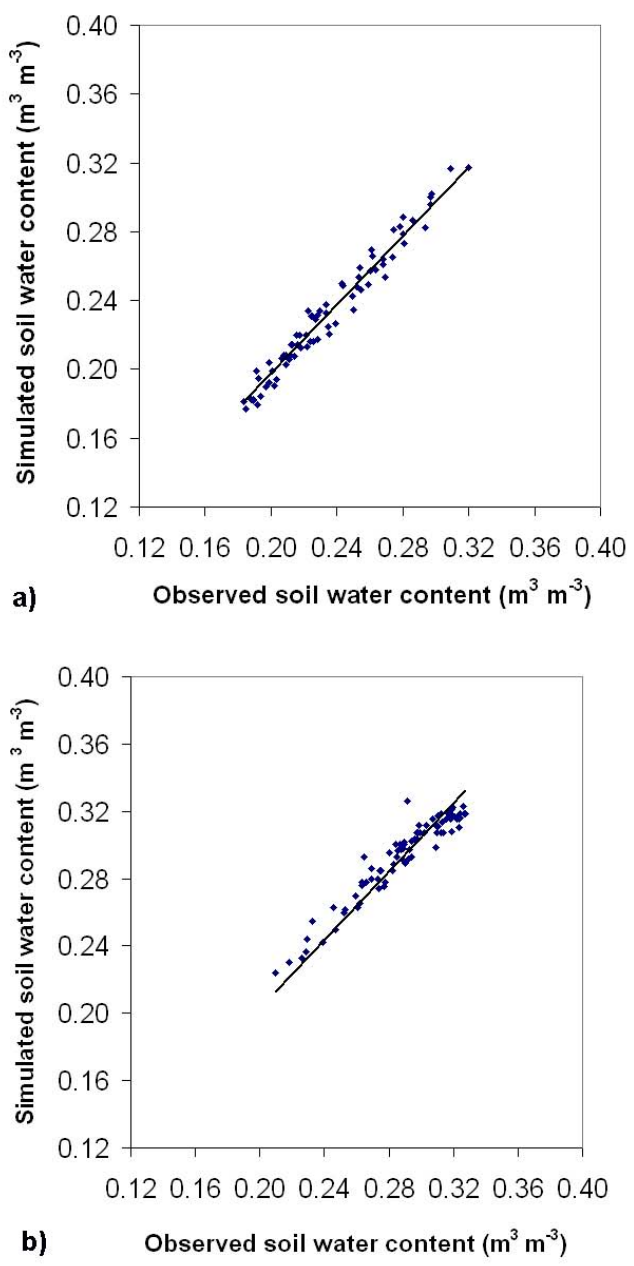

Fig. 5. Linear regression forced to the origin comparing the observed and model predicted soil water content for all treatments used for calibration (a) and validation (b).

content are much smaller than those for $\mathrm{ET}_{o, \mathrm{WF}}$. It results that differences in $b$ values are very small when the $\mathrm{ET}_{o \text {,obs }}$ or $\mathrm{ET}_{o, \mathrm{WF}}$ data sets are used. The determination coefficients range 0.78 to 0.97 for the first year and 0.74 to 0.93 for the second, and are slightly smaller than those obtained for the calibration and validation of the model.

When computations are performed with $\mathrm{ET}_{o, \mathrm{WF}}$ the estimation errors RMSE and RE are small but slightly larger than those using $\mathrm{ET}_{o, \mathrm{obs}}$. Considering all treatments, RMSE averages 0.010 and $0.012 \mathrm{~m}^{3} \mathrm{~m}^{-3}$ for respectively 2006 and 2007, while RE is 0.041 and 0.043 for the same years (Table 6). These good results are confirmed by the $d$ and EF indices, whose values range respectively from 0.89 to 0.98 and from 0.55 to 0.93 when considering both years. Results in Fig. 7 confirm the goodness of fitting for all treatments simulated.

These results indicate that when the soil water balance is performed with a properly calibrated model it is possible to use as model input the reference evapotranspiration estimates $\mathrm{ET}_{o}, \mathrm{WF}$ with appropriate accuracy for irrigation scheduling purposes. It is then possible to run a model in real time with daily inputs of $\mathrm{ET}_{o, \mathrm{WF}}$ and actual observations of precipitation. Further research is required to combine a spatialized $\mathrm{ET}_{o, \mathrm{WF}}$ estimation as referred above with the operation of the irrigation scheduling model with a spatial GIS database as formerly tested (Fortes et al., 2005).

\section{Conclusions}

This study has shown that the reference evapotranspiration can be estimated from daily weather forecast messages using the FAO Penman Monteith equation in a non-synoptic location, however with less accuracy then for synoptic stations. With this approach, the global radiation is estimated from the difference between the forecasted maximum and minimum temperatures, the actual vapour pressure is estimated from the forecasted minimum temperature and the wind speed is obtained from converting the common wind scales used by the China Meteorological Administration into wind speed. The estimated $\mathrm{ET}_{o}$ shows a RMSE of $0.77 \mathrm{~mm} \mathrm{~d}^{-1}$ and the indicators $\mathrm{EF}$ and $d$ for the goodness of fitting average 0.75 and 0.94 , respectively. These indicators show that using daily weather forecasts produces estimates for $\mathrm{ET}_{o}$ comparable with those computed with observed weather data, particularly when some weather variables are not observed. These results indicate that daily forecast messages may be used for $\mathrm{ET}_{o}$ computations for non-synoptic locations which provide for adopting $\mathrm{ET}_{o}, \mathrm{WF}$.for real time irrigation scheduling models. However, further studies on the spatial variation of $\mathrm{ET}_{o, \mathrm{WF}}$ estimates are required to better assess the conditions to use them for real-time irrigation scheduling at project, basin or regional level.

To assess the impacts of using $\mathrm{ET}_{o, \mathrm{WF}}$ estimates instead of $\mathrm{ET}_{o, \mathrm{obs}}$ when modelling the soil water balance, the model ISAREG was first calibrated and validated for several winter wheat treatments and using $\mathrm{ET}_{o, \text { obs }}$ as input data for the crop seasons of 2005-2006 and 2006-2007. Simulations were performed for the period after soil defrost and crop reviving after the winter, thus during the development, mid-season and end-season crop stages. The respective results show that the simulated soil water content matches well with the observed values, i.e., the model accurately simulates the soil water balance of the wheat crop when the calibrated parameters are used.

The results of the simulations for both crop seasons and the same irrigation treatments using $\mathrm{ET}_{o, \mathrm{WF}}$ have also shown that the simulated soil water content matches well with the observed values. However, the over- or under estimation of $\mathrm{ET}_{o}$ produces, respectively, a small under- and overestimation of the simulated soil water content. In the present study, the RMSE values ranged from 0.007 to $0.016 \mathrm{~m}^{3} \mathrm{~m}^{-3}$, which indicates a very good modelling accuracy. Other 

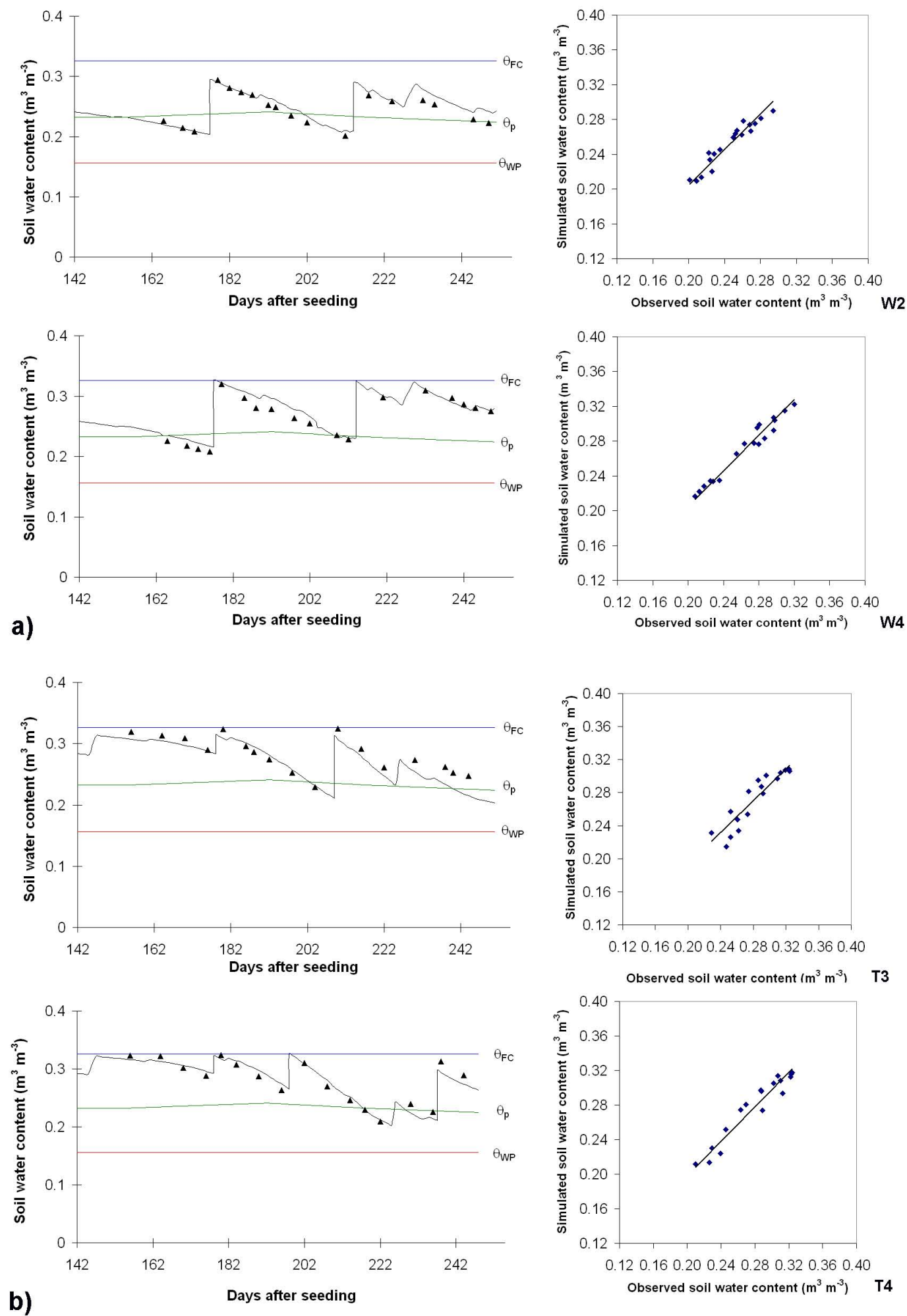

Fig. 6. Comparing the soil water content observed and predicted by the model when $\mathrm{ET}_{o}$ was estimated from weather forecast messages ( $\mathrm{ET}_{o, \mathrm{WF}}$ ) for: (a) two treatments in 2005-2006 (W2 and W4); and (b) two other treatments in 2006-2007 (T3 and T4). On the left: the daily course of the soil water; on the right, the respective regressions forced to the origin. The lines of $\theta_{\mathrm{FC}}, \theta_{p}$ and $\theta_{\mathrm{WP}}$ refer to the soil water content at field capacity, at the depletion fraction for no stress and at the wilting point, respectively. 


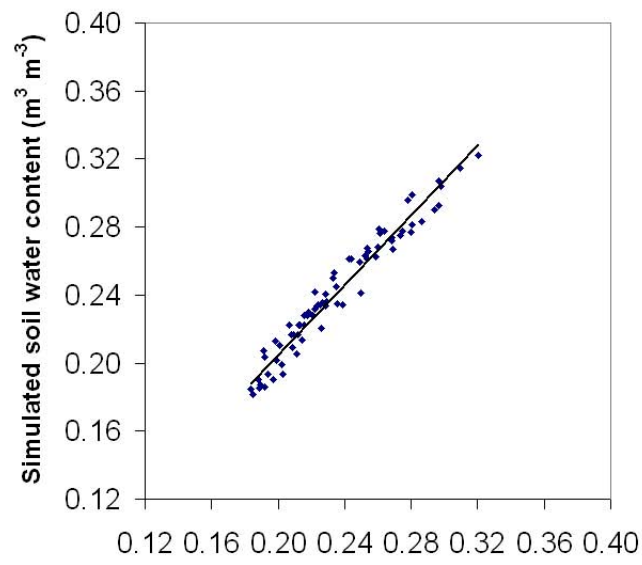

a) Observed soil water content $\left(\mathrm{m}^{3} \mathrm{~m}^{-3}\right)$

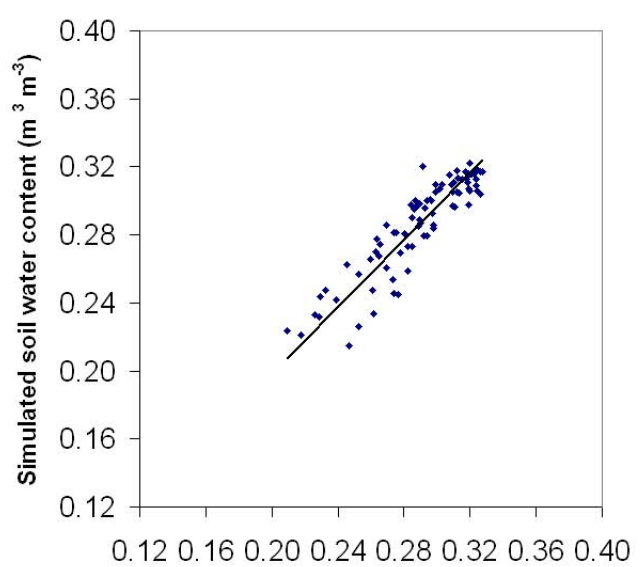

b) Observed soil water content $\left(\mathrm{m}^{3} \mathrm{~m}^{-3}\right)$

Fig. 7. Linear regression forced to the origin comparing the observed and model predicted soil water content when $\mathrm{ET}_{o}$ was computed from weather forecast messages $\left(\mathrm{ET}_{o}, \mathrm{WF}\right)$ for all treatments of 2005-2006 (a) and 2006-2007 (b).

model fitting indicators confirm these results, with EF ranging 0.55 to 0.92 and $d$ ranging 0.89 to 0.98 . It can be concluded that when the soil water balance is performed with a properly calibrated model it is appropriate to use as model input the reference evapotranspiration estimated from daily weather forecast messages. However, further research on the spatial variation of $\mathrm{ET}_{o}, \mathrm{WF}$ estimates and of their impacts on model predictions of the soil water content is required and is being developed to better assess the conditions for using those $\mathrm{ET}_{o}$ estimates for real-time irrigation scheduling at project, basin or regional level.

Acknowledgements. This research was supported by the Projects of Development Plan of the State Key Fundamental Research (No. 2006CB403405) and by the National 863 Plans Project No. 2006AA100208-4. The collaborative Sino-Portuguese project on "Water Saving Irrigation: Technologies and Management" is also acknowledged.

Edited by: G. Blöschl

\section{References}

Allen, R. G., Pereira, L. S., Raes, D., and Smith, M.: Crop Evapotranspiration: Guidelines for computing crop requirements. FAO, Irrigation and Drainage Paper No. 56, FAO, Rome, Italy, 300 pp., 1998.

Allen, R. G., Pruitt, W. O., Wright, J. L., Howell, T. A., Ventura, F., Snyder, R., Itenfisu, D., Steduto, P., Berengena, J., Baselga, J., Smith, M., Pereira, L. S., Raes, D., Perrier, A., Alves, I., Walter, I., and Elliott, R.: A recommendation on standardized surface resistance for hourly calculation of reference ETo by the FAO56 Penman-Monteith method, Agric. Water Manage., 81, 122, 2006.

Angström, A.: Solar and terrestrial radiation, Q. J. Roy. Meteor. Soc., 50, 121-125, 1924.

Bai, M. J., Xu, D., Li, Y. N., and Li, J. S.: Evaluation of spatial and temporal variability of infiltration on a surface irrigation field, J. Soil Water Conserv, 19(5), 120-123, 2005 (in Chinese).

Cabelguenne, M., Debaeke, Ph., Puech, J., and Bose, N.: Real time irrigation management using the EPIC-PHASE model and weather forecasts, Agric. Water Manage., 32, 227-238, 1997.

Cai, L. G., Qian, Y., and Xu, D.: Sustaining irrigated agriculture in China, in: Sustainability of Irrigated Agriculture, edited by: Pereira, L. S., Feddes, R. A., Gilley, J. R., and Lesaffre, B., NATO ASI Series, Kluwer, Dordrecht, 581-587, 1996.

Cai, J. B., Liu, Y., Lei, T., and Pereira, L. S.: Estimating reference evapotranspiration with the FAO Penman-Monteith equation using daily weather forecast messages, Agric. For. Meteo., 145(12), 22-35, 2007.

Calera Belmonte, A., Jochum, A. M., Cuesta Carcia, A., Montoro Rodriguez, A., and López Fuster, P.: Irrigation management from space: Towards user-friendly products, Irrig. Drain. Syst., 19, 337-354, 2005.

Cancela, J. J., Cuesta, T. S., Neira, X. X., and Pereira, L. S.: Modelling for improved irrigation water management in a temperate region of Northern Spain, Biosyst. Eng., 94(1), 151-163, 2006.

Chavez, J., Neale, C. M. U., Prueger, J. H., and Kustas, W. P.: Daily evapotranspiration estimates from extrapolating instantaneous airborne remote sensing ET values, Irrig. Sci., 27, 67-81, 2008.

Cholpankulov, E. D., Inchenkova, O. P., Paredes, P., and Pereira, L. S.: Cotton irrigation scheduling in Central Asia: Model calibration and validation with consideration of groundwater contribution, Irrig. Drain., 57, 516-532, 2008.

CMA: Surface Meteorological Observation Criterion, China Meteorological Administration, Beijing, 2003 (in Chinese).

Consoli, S., D'Urso, G., and Toscano, A.: Remote sensing to estimate ET-fluxes and the performance of an irrigation district in southern Italy, Agric. Water Manage., 81, 295-314, 2006.

Courault, D., Seguin, B., and Olioso, A.: Review on estimation of evapotranspiration from remote sensing data: From empirical to numerical modeling approaches, Irrig. Drain. Syst., 19, 223-249, 2005.

Ding, K. L. An investigation into the effects of soil management on soil properties and crop growth in the Huang-Huai-Hai Plain in North China. PhD dissertation, Silsoe College, Cranfield University, 1998.

Donatelli, M., Bellocchi, G., and Fontana, F.: RadEst3.00: software to estimate daily radiation data from commonly available meteorological variables, Eur. J. Agron., 18, 363-367, 2003. 
Fernando, R. M., Pereira, L. S., Liu, Y., Li, Y. N., and Cai, L. G.: Reduced demand irrigation scheduling under constraint of the irrigation method, in: Water and the Environment: Innovation Issues in Irrigation and Drainage (1st Inter-Regional Conf. Environment-Water, Lisbon), edited by: Pereira, L. S. and Gowing, J. W., E\& FN Spon, London, 407-414, 1998.

Fortes, P. S., Platonov, A. E., and Pereira, L. S.: GISAREG - A GIS based irrigation scheduling simulation model to support improved water use, Agric. Water Manage., 77, 159-179, 2005.

Garatuza-Payan, J. and Watts, C. J.: The use of remote sensing for estimating ET of irrigated wheat and cotton in Northwest Mexico, Irrig. Drain. Syst., 19, 301-320, 2005.

Gowda, P. H., Chavez, J. L., Colaizzi, P. D., Evett, S. R., Howell, T. A., and Tolk, J. A.: ET mapping for agricultural water management: Present status and challenges, Irrig. Sci., 26, 223-237, 2008.

Gowing, J. W. and Ejieji, C. J.: Real-time scheduling of supplemental irrigation for potatoes using a decision model and short-term weather forecasts, Agric. Water Manage., 47, 137-153, 2001.

Hunsaker, D. J., Pinter, P. J., and Kimball, B. A.: Wheat basal crop coefficients determined by normalized difference vegetation index, Irrig. Sci., 24, 1-14, 2005.

Jabloun, M. and Sahli, A.: Evaluation of FAO-56 methodology for estimating reference evapotranspiration using limited climatic data: Application to Tunisia, Agric. Water Manage., 95(6), 707715,2008

Legates, D. R. and MacCabe, G. J.: Evaluating of the "goodness fit" measures in hydrologic and hydroclimatic model validation, Water Resour. Res., 35, 233-241, 1999.

Liu, Y. and Pereira, L. S.: Calculation methods for reference evapotranspiration with limited weather data, J. Hydrol. Eng., 2001(3), 11-17, 2001 (in Chinese).

Liu, Y. and Pereira, L. S.: Optimization of irrigation scheduling considering the constraints of surface irrigation technology, Transactions of the CSAE, 19(4), 74-79, 2003 (in Chinese).

Liu, Y., Teixeira, J. L., Zhang, H. J., and Pereira, L. S.: Model validation and crop coefficients for irrigation scheduling in the North China Plain, Agric. Water Manage., 36, 233-246, 1998.

Liu, Y., Cai, J. B., Cai, L. G., Fernando, R. M., and Pereira, L. S.: Improved irrigation scheduling under constraints of the irrigation technology, in: Theory and Practice of Water-Saving Agriculture (Proc. Chinese-Israeli Int. Workshop, Beijing), edited by: Huang, G. H., Waterpub, Beijing, 168-181, 2000.

Liu, Y., Cai, J. B., Xu, D., Cai, L. G., and Pereira, L. S.: Strategies for irrigation scheduling and water balance for an irrigation district at the lower reaches of the Yellow River, in: Land and Water Management: Decision Tools and Practices (Proc. 7th CIGR Inter-Regional Conf. Environment and Water, Beijing), edited by: Huang, G. H. and Pereira, L. S., China Agriculture Press, Beijing, Vol. 1, 124-134, 2004.

Liu, Y., Pereira, L. S., and Fernando, R. M.: Fluxes through the bottom boundary of the root zone in silty soils: Parametric approaches to estimate groundwater contribution and percolation, Agric. Water Manage., 84, 27-40, 2006.

Loague, K. and Green, R. E.: Statistical and graphical method for evaluating solute transport model: overview and application, J. Contin. Hydro., 7, 51-73, 1991.

Nakayama, T., Yang, Y. H., Watanabe, M., and Zhang, X. Y.: Simulation of groundwater dynamics in the North China Plain by coupled hydrology and agricultural models, Hydrol. Processes, 20, 3441-3466, 2006.

Oweis, T., Rodrigues, P. N., and Pereira, L. S.: Simulation of supplemental irrigation strategies for wheat in Near East to cope with water scarcity, in: Tools for Drought Mitigation in Mediterranean Regions, edited by: Rossi, G., Cancelliere, A., Pereira, L. S., Oweis, T., Shatanawi, M., and Zairi, A., Kluwer, Dordrecht, 259-272, 2003.

Pereira, L. S., Musy, A., Liang, R. J., and Hann, M. (Eds.): Water and Soil Management for Sustainable Agriculture in the North China Plain, ISA, Lisbon, 405 pp., 1998.

Pereira, L. S., Cai, L. G., and Hann, M. J.: Farm water and soil management for improved water use in the North China Plain, Irrig. Drain., 52(4), 299-317, 2003a.

Pereira, L. S., Teodoro, P. R., Rodrigues, P. N., and Teixeira, J. L.: Irrigation scheduling simulation: the model ISAREG, in: Tools for Drought Mitigation in Mediterranean Regions, edited by: Rossi, G., Cancelliere, A., Pereira, L. S., Oweis, T., Shatanawi, M., and Zairi, A., Kluwer, Dordrecht, 161-180, 2003 b.

Pereira, L. S., Gonçalves, J. M., Dong, B., Mao, Z., and Fang, S. X.: Assessing basin irrigation and scheduling strategies for saving irrigation water and controlling salinity in the Upper Yellow River Basin, China, Agric. Water Manage., 93(3), 109-122, 2007.

Popova, Z., Eneva, S., and Pereira, L. S.: Model validation, crop coefficients and yield response factors for maize irrigation scheduling based on long-term experiments, Biosyst. Eng., 95(1), 139149, 2006a.

Popova, Z., Kercheva, M., and Pereira, L. S.: Validation of the FAO methodology for computing ETo with missing climatic data. Application to South Bulgaria, Irrig. Drain., 55(2), 201-215, $2006 \mathrm{~b}$.

Randin, N., Musy, A., and Wang, S.: Modeling groundwater behavior for a Chinese irrigated perimeter, ICID Journal, 48(3), 27-38, 1999.

Ray, S. S. and Dadhwal, V. K.: Estimation of crop evapotranspiration of irrigation command area using remote sensing and GIS, Agric. Water Manage., 49(3), 239-249, 2001.

Santos, C., Lorite, I. J., Tasumi, M., Allen, R. G., and Fereres, E.: Integrating satellite-based evapotranspiration with simulation models for irrigation management at the scheme level, Irrig Sci., 26, 27-288, 2008.

Stöckle, C. O., Donatelli, M., and Nelson, R.: CropSyst, a cropping systems simulation model, Eur. J. Agron., 18(3-4), 289307, 2003.

Stöckle, C. O., Kjelgaard, J., and Bellocchi, G.: Evaluation of estimated weather data for calculating Penman-Monteith reference evapotranspiration, Irrig. Sci., 23, 39-46, 2004.

Tasumi, M. and Allen, R. G.: Satellite-based ET mapping to assess variation in ET with timing of crop development, Agric. Water Manage., 88(1), 54-62, 2007.

Teixeira, J. L. and Pereira, L. S.: ISAREG, an irrigation scheduling model, ICID Bull., 41(2), 29-48, 1992.

Vanclooster, M., Viaene, P., Diels, J., and Feyen, J.: A deterministic validation procedure applied to the integrated soil crop model WAVE, Ecol. Model, 81, 183-195, 1995.

Victoria, F. B., Viegas Filho, J. S., Pereira, L. S., Teixeira, J. L., and Lanna, A. E.: Multi-scale modeling for water resources planning and management in rural basins, Agric. Water Manage., 77, 420,2005 
Wang, E., Yu, Q., Wu, D., and Xia, J.: Climate, agricultural production and hydrological balance in the North China Plain, Int. J. Climatol., 28, 1959-1970, 2008.

Wilks, D. S. and Wolfe, D. W.: Optimal use and economic value of weather forecasts for lettuce irrigation in a humid climate, Agric. For. Meteo., 89, 115-129, 1998.

$\mathrm{Xu}, \mathrm{D}$. and Mermoud, A.: Modeling of the soil water balance based on time-dependent hydraulic properties under different tillage practices, Agric. Water Manage., 63, 139-151, 2003.
Zairi, A., El Amami, H., Slatni, A., Pereira, L. S., Rodrigues, P. N., and Machado, T.: Coping with drought: deficit irrigation strategies for cereals and field horticultural crops in Central Tunisia, in: Tools for Drought Mitigation in Mediterranean Regions, edited by: Rossi, G., Cancelliere, A., Pereira, L. S., Oweis, T., Shatanawi, M., and Zairi, A., Kluwer, Dordrecht, 181-201, 2003.

Zhao, W., Zhao, W. J., and Zhang, Z. F.: The dynamic change and sustainable use of shallow groundwater in Beijing, Journal of Capital Normal University 25(3), 92-95, 2004 (in Chinese). 